\title{
Pegadas hídrica e de Carbono de Produtos agrícolas: estudo da ÁGUa de COCO IN NATURA
}

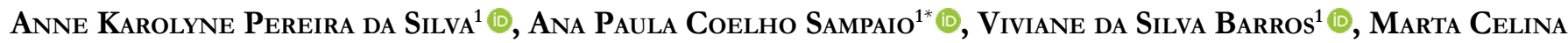 \\ Linhares Sales ${ }^{1}\left[\right.$ [) Francisco Suetônio Bastos Sales $^{1}$ [0, Maria Cléa Brito de Figueirêdo ${ }^{2}$ [D
}

1 Universidade Federal do Ceará, Centro de Ciências, Departamento de Geografia, Canpus do Pici - Bloco 911, Pici, Fortaleza, CE, Brasil, 60455760. 2 Embrapa Agroindústria Tropical. Rodovia CE-253, Km 42, s/n - Zona Rural, Pacajus - CE, 62870-000.

* Autorpara correspondência: anapaulacsampaio@gmail.com

Recebido em 05 de junho de 2019. Aceito em 27 de julho de 2020. Publicado em 31 de julho de 2020.

\begin{abstract}
Resumo - Este trabalho avalia as pegadas de carbono e hídrica da água de coco. Foram coletados dados em fazendas do Ceará, localizadas nos municípios de Acaraú, Camocim, Paraipaba e Trairi, além de analisado o sistema de produção publicado na literatura para coqueiro anão verde. As pegadas são calculadas com base nas normas ISO 14046/67, considerando a produção de $1 \mathrm{~L}$ de água de coco. A pegada de carbono é avaliada pela categoria mudanças climáticas (IPCC), enquanto o perfil de pegada hídrica abrange as seguintes categorias e métodos de avaliação: escassez hídrica (AWARE), toxicidade e ecotoxicidade (USETox), eutrofização marinha e em águas doces (ReCiPe). Os resultados mostram que a água de coco produzida em Acaraú e Camocim apresentam as menores pegada de carbono e Paraipaba a menor pegada hídrica em relação à produzida na fazenda de referência. Já a água de coco de Trairi obteve a pior pegada de carbono, enquanto Camocim, a pior pegada hídrica. A maior redução da pegada de carbono ocorre quando o pomar de coco é instalado em área desmatada e/ou cultivada com cultura temporária, há mais de 20 anos. No caso da pegada hídrica, as maiores reduções ocorrem com menor uso de fertilizante nitrogenado e água na irrigação.
\end{abstract}

Palavras-chave: Impactos ambientais; Avaliação do ciclo de vida; Coco verde; Ceará.

WATER AND CARBON FOOTPRINTS OF AGRICULTURE PRODUCTS: A STUDY OF FRESH COCONUT WATER

Aвstract - This work assesses the carbon and water footprints of coconut water. Data were collected from farms in Ceará, located in the municipalities of Acaraú, Camocim, Paraipaba and Trairi, in addition to analyzing the production system published in the literature for green dwarf coconut trees. Footprints are calculated based on ISO 14046/67 standards, considering the production of $1 \mathrm{~L}$ of coconut water. The carbon footprint is assessed by the climate change category (IPCC), while the water footprint profile covers the following categories and assessment methods: water scarcity (AWARE), toxicity and ecotoxicity (USETox), marine and freshwater eutrophication (ReCiPe). The results show that the coconut water produced in Acaraú and Camocim have the smallest carbon footprint and Paraipaba the smallest water footprint in relation to that produced on the reference farm. Trairi's coconut water had the worst carbon footprint, while Camocim, the worst water footprint. The greatest reduction in the carbon footprint occurs when the coconut orchard is installed in an area that has been deforested and/or cultivated with a temporary crop for more than 20 years. In the case of the water footprint, the greatest reductions occur with less use of nitrogen fertilizer and water for irrigation.

KEYwORDs: Environmental impact; Life cycle assessment; Green coconut; Ceará. 
HuEllas hídRICAS Y DE CARbONO DE PRODUCTOS AGRíCOlAS: ESTUdio DEL AGUA DE COCO IN NATURA

Resumen - Este trabajo evalúa las huellas de carbono e hídrica del agua de coco. Se recolectaron datos de fincas en Ceará, ubicadas en los municipios de Acaraú, Camocim, Paraipaba y Trairi, además de analizar el sistema de producción publicado en la literatura para cocoteros enanos verdes. Las huellas se calculan según las normas ISO 14046/67, considerando la producción de 1 litro de agua de coco. La huella de carbono es evaluada por la categoría de cambio climático (IPCC), mientras que el perfil de huella hídrica abarca las siguientes categorías y métodos de evaluación: escasez de agua (AWARE), toxicidad y ecotoxicidad (USETox), eutrofización marina y de agua dulce (ReCiPe). Los resultados muestran que el agua de coco producida en Acaraú y Camocim tiene la menor huella de carbono y Paraipaba la menor huella hídrica en relación con la producida en la finca de referencia. El agua de coco de Trairi tenía la peor huella de carbono, mientras que Camocim, la peor huella hídrica. La mayor reducción en la huella de carbono ocurre cuando el huerto de cocoteros se instala en un área que ha sido deforestada y / o cultivada con un cultivo temporal durante más de 20 años. En el caso de la huella hídrica, las mayores reducciones ocurren con menos uso de fertilizantes nitrogenados y agua en el riego.

Palabras clave: Impactos ambientales; Evaluación del ciclo de vida; Coco verde; Ceará.

\section{INTRODUÇÃO}

A avaliação da pegada hídrica e de carbono de produtos é um instrumento de gestão ambiental que vem sendo cada vez mais adotado por empresas em todo o mundo, em especial do setor de alimentos (Tesco 2019; Luske 2010; Sikirica 2011). Isso decorre da crescente conscientização da sociedade, consumidores e produtores, sobre as consequências das mudanças climáticas, escassez e baixa qualidade da água.

Entende-se por pegada hídrica o perfil de impactos relacionados à água, decorrentes do ciclo de vida de um produto (ISO 14046 2014). Já a pegada de carbono avalia o impacto do ciclo de vida de um produto nas mudanças climáticas (ISO 14067 2013).

Estudos de pegada hídrica e de carbono podem ser utilizados para certificação ambiental de produtos, de acordo com a ISO 14025 (2006), quando seguem os princípios e procedimentos estabelecidos pelas normas ISO 14046 e 14067 para condução do estudo. Esses estudos podem também ser empregados para identificação dos processos mais poluentes, associados a um produto, e identificação de oportunidades de melhoria (Carneiro et al. 2019).

Nesse contexto, a água de coco é um importante produto comercial para o Brasil que vem ganhando mercado internacional nos últimos anos (Brainer 2018). Para que as exportações desse produto possam crescer, especialmente no mercado europeu, é importante se conhecer a pegada desse produto e incentivar políticas e práticas que gerem menores impactos ambientais na produção do coco verde.

A produção de coco verde é uma atividade econômica de grande importância para o Nordeste brasileiro, sendo o Ceará o terceiro maior produtor nacional. Em 2017, a produção de coco no Ceará contribuiu com 12\% da produção nacional, o equivalente a 186.732 toneladas (IBGE 2018). Os principais municípios com maior produção de coco no Ceará, nos últimos dez anos, foram Paraipaba (14,1\%), Trairi (11,1\%), Itarema $(7,1 \%)$ e Acaraú (6,8\%).

Em todo o Nordeste, o coco verde é cultivado principalmente em áreas litorâneas, utilizando-se fertirrigação em solos arenosos pobres em nutrientes para suprir as necessidades da cultura. No Ceará, o coco é a principal cultura irrigada, utilizando-se entre 100 e 200L de água por planta/dia (Miranda et al. 2007).

Este trabalho avalia e compara as pegadas de carbono e hídrica da água de coco verde in natura produzida em fazendas localizadas nos principais munícipios produtores do Ceará. Realiza-se uma análise comparativa dessas fazendas com uma fazenda de referência, definida a partir de sistema de produção proposto por Fontes e Ferreira 
(2016) para produção de coco verde no Nordeste. São identificados municípios e processos críticos, assim como sugeridas ações para redução dessas pegadas.

A metodologia de avaliação das pegadas de carbono e hídrica descrita nesse trabalho poderá ser aplicada no estudo de outros produtos agrícolas. Os resultados obtidos podem ser utilizados como base para programas de certificação de carbono e hídrica em empresas específicas produtoras de coco verde, sendo também relevantes para priorização de ações governamentais voltadas para a melhoria de eficiência no uso de insumos e redução de impactos na produção de coco verde.

Estudos abrangendo as pegadas hídrica e de carbono de produtos brasileiros são escassos. Carneiro et al. (2019) avaliaram as pegadas de carbono e hídrica da manga produzida no Vale do São Francisco, enquanto Sampaio et al. (2018) focaram na pegada hídrica da água de coco produzida em fazendas do Nordeste. Nesse último estudo, a água de coco produzida no Ceará resultou na maior pegada hídrica. Porém, nesse estudo não foi avaliada a pegada de carbono, nem identificadas as regiões produtoras e os processos mais críticos na avaliação da pegada hídrica. O presente trabalho cobre essa lacuna de informações, buscando propor ações que tornem mais competitiva a água de coco produzida no Ceará.

\section{Materiais e métodos}

Este estudo seguiu as recomendações das normas ISO 14067 (2013) e 14046 (2014), as quais padronizam os estudos de pegada de carbono e hídrica de produtos, respectivamente. Essas normas seguem os passos da avaliação de ciclo de vida (ACV): definição de objetivo e escopo, inventário ambiental, avaliação de impactos e interpretação dos resultados; de acordo com o estabelecido nas normas ISO 14040 e 14044 (2006a e b).

\section{Unidade funcional e escopo do estudo}

A unidade funcional é de $1 \mathrm{~L}$ de água de coco em um ano médio de produção, considerando um pomar com vida útil de 17 anos. Os dados foram coletados para as três fases do pomar: implantação (1 - 2 anos), sem produção; crescimento (3 - 5 anos), quando se inicia a produção de coco; e estabilização (6 - 17 anos), quando a produção de coco verde se estabiliza.

A fronteira do estudo abrange os processos de produção e transporte de insumos (agroquímicos, água e energia) utilizados nas fazendas, a mudança do uso da terra para instalação do coqueiral, e a produção de coco verde. $\mathrm{Na}$ produção agrícola, são contempladas as atividades de preparo do solo, plantio, tratos culturais, irrigação, adubação e controle fitossanitário.

\section{Caracterização das fazendas}

O estudo foi realizado em quatro fazendas, localizadas nos municípios de Acaraú, Camocim, Paraipaba e Trairi. Os gerentes dessas fazendas forneceram dados sobre uso de insumos e produção alcançada, considerando os últimos cinco anos (2012 a 2017).

A irrigação nessas fazendas é feita por microaspersores (um por planta) e acontece durante o período de estiagem no Estado, que corresponde ao intervalo de junho a janeiro, variando somente a quantidade de água aplicada por planta em cada fazenda, que por sua vez depende da disponibilidade hídrica da região. 
Já a aplicação dos defensivos acontece sempre após a colheita, que no caso das fazendas analisadas somam um total de nove aplicações ao longo do ano. Além dos defensivos comuns a essa cultura, também é empregada uma solução de detergente com extrato vegetal, óleo de coco ou de algodão, para auxiliar no controle fitossanitário.

Os manejos culturais nas fazendas se resumem as pulverizações e roçagens mecanizadas, além da colheita realizada manualmente.

\section{Coleta dos dados de inventário}

O levantamento dos dados para a composição do inventário ambiental, relacionadas com as quantidades de insumos utilizados na produção de coco, além da produção anual de coco e água de coco, foi dividido em duas etapas:

i) a primeira consistiu em compor o sistema de referência deste estudo, a partir dos dados de Fontes e Ferreira (2016) de um sistema de produção indicado para uma fazenda de coco verde localizada na região Nordeste, por esse ser um estudo único e completo, pois comtempla as etapas de adubação, irrigação, manejo e controle de pragas, sobre a cultura do coqueiro;

ii) a segunda compreendeu a coleta de dados primários (quantidade de insumos utilizados no campo) nas quatro fazendas que aceitaram participar deste estudo, por meio da aplicação de questionário aos produtores em visitas técnicas.

Para facilitar a análise dos resultados, definiu-se que a água de coco proveniente de cada fazenda será denominada: A - para água da fazenda de Acaraú; C - para água da fazenda de Camocim; P para água da fazenda de Paraipaba; e $\mathrm{T}$ - para água da fazenda de Trairi.

As emissões de gás carbônico $\left(\mathrm{CO}_{2}\right)$, metano $\left(\mathrm{CH}_{4}\right)$, monóxido de carbono $(\mathrm{CO})$, óxidos de nitrogênio $\left(\mathrm{NO}_{\mathrm{x}}\right)$ e óxido nitroso $\left(\mathrm{N}_{2} \mathrm{O}\right)$ relacionadas com a mudança no uso da terra e a produção agrícola de coco verde foram estimadas, utilizando a metodologia indicada pelo IPCC (2007). As estimativas dessas emissões foram realizadas considerando-se um hectare de terreno cultivado durante um ano médio. O período de base para o cálculo das emissões foi determinado em 17 anos, incluindo as fases de implantação, crescimento e estabilização. Dentro do período base de cálculo as atividades consideradas foram transformação do uso da terra (de caatinga para área de agricultura, em que há perda de biomassa por corte e queima, e mineralização da matéria orgânica), queima de combustíveis fósseis pelo maquinário, e uso de fertilizantes nitrogenados (fertilizantes sintéticos e $\mathrm{N}$ proveniente da incorporação de resíduos culturais incorporados ao solo). De modo geral, o IPCC (2007) apresenta equações que permitem calcular as emissões de GEE nas atividades consideradas durante o período de produção agrícola, resultando na massa de GEE de cada processo. Ao final, as emissões totais são expressas em $\mathrm{Kg}$ de $\mathrm{CO}_{2}$ equivalente.

Além das emissões de GEE, estimaram-se emissões de amônia $\left(\mathrm{NH}_{3}\right)$ (Modelo Agrammon) e de óxidos de nitrogênio $\left(\mathrm{NO}_{\mathrm{x}}\right.$ ) (Modelo SQCB-NO ) para o ar, por Nemecek e Schnetzer (2011). Emissões de fósforo (P) (processos erosivos), fosfato $\left(\mathrm{PO}_{4}\right)$ (escoamento e lixiviação) e nitrato $\left(\mathrm{NO}_{3}\right)$ para a água, por Nemecek e Schnetzer (2011) e Emmenegger et al. (2009). E as emissões de metais pesados para água e solo, e de pesticidas para o solo, seguiram as orientações de Nemecek e Schnetzer (2011). Foram utilizados dados secundários para a realização desse estudo. Os dados da fazenda de referência são dados da literatura. As informações relacionadas à produção dos insumos, as atividades agrícolas e transporte foram obtidas na base de dados do Ecoinvent v. 3.3 (Frischknecht e Jungbluth 2007). 
Buscando analisar a eficiência de uso da água na irrigação das fazendas, calculou-se a necessidade hídrica do coqueiro, visto que, um suprimento adequado de água constitui principal exigência dessa cultura (Amorim et al. 2016). A estimativa da quantidade de água a ser aplicada foi realizada em duas etapas que são descritas a seguir.

Primeiro, foi calculada a evapotranspiração da cultura (ETc), que representa o consumo real de água pela cultura. Em que ETc se relaciona diretamente com as fases de desenvolvimento da cultura (Kc), com o coeficiente de redução da evapotranspiração $(\mathrm{Kr})$ e com a evapotranspiração de referência (ETo) de cada município, através do seu produto, agrupados por região (I - Acaraú/Camocim e II - Paraipaba/Trairi) (Miranda e Gomes 2006).

Em seguida, calculou-se a lâmina bruta, ou seja, a lâmina de água total aplicada, prevendo-se as perdas e a uniformidade de distribuição, e considerando uma eficiência de irrigação localizada por microaspersão de $90 \%$ (Miranda e Gomes 2006).

\section{Avaliação das pegadas hídrica e de carbono}

As categorias de impactos consideradas na avaliação do perfil de pegada hídrica foram: escassez hídrica $\left(\mathrm{m}^{3}\right.$ eq/L de água de coco), eutrofização marinha (Kg N/L de água de coco), eutrofização de águas doces (Kg P/L de água de coco), toxicidade humana, cancerígena e não-cancerígena (CTUh/L de água de coco) e ecotoxicidade em águas doces (CTUe/L de água de coco).

O método USEtox (Rosenbaum et al. 2008) foi utilizado para a avaliação da toxicidade humana e da ecotoxicidade, utilizando-se fatores para impactos cancerígenos, não cancerígenos e impactos no ambiente aquático. O método ReCiPe midpont (ILCD 2011), versão hierarquizada, foi empregado na avaliação da eutrofização, fornecendo fatores para os compostos nitrogenados e fosfatados.

Por fim, utilizou-se o método AWARE (Boulay et al. 2018) na avaliação do impacto na escassez hídrica. Esse método analisa o potencial de escassez hídrica em nível de bacia hidrográfica, considerando não somente a quantidade de água retirada do local, mas também a disponibilidade desse recurso para atender a demanda humana e ecossistêmica.

Os fatores de caracterização (FC) do AWARE refletem a disponibilidade hídrica remanescente em uma bacia hidrográfica, uma vez que a demanda dos ecossistemas aquáticos e a humana tenham sido satisfeitas (UNEP 2016). Neste trabalho, foram utilizadas duas estratégias para o cálculo da escassez hídrica, buscando-se analisar alterações nos resultados: i) uso dos FC mensais, multiplicando-se o consumo de água de cada mês irrigado, pelo fator de cada mês e de cada bacia onde a fazenda está inserida, sendo o valor total do impacto o somatório dos impactos de cada mês; e ii) multiplicação do consumo anual médio de água na fazenda pelo FC anual.

$\mathrm{Na}$ Avaliação do Ciclo de Vida (ACV) busca-se avaliar os impactos potenciais de um processo ou produto através de estimativas relacionadas a uma determinada categoria de impacto. No caso da pegada hídrica são as categorias relacionadas ao uso da água no processo/produto avaliado, neste estudo, o uso da água no cultivo do coco para a produção de $1 \mathrm{~L}$ de água de coco. Isso significa que todos os potenciais impactos referem-se à produção de $1 \mathrm{~L}$ de água de coco em cada uma das fazendas avaliadas. A metodologia ACV, até o momento, disponibiliza somente a análise de categorias de impacto que se limitam a análise de água superficiais, sendo assim, uma limitação deste estudo, pois embora exista uma interação importante entre as águas de chuvas, superficiais e subterrâneas, formando componentes hidrológicos interligados, a origem da água é omitida nos fatores de caracterização de cada uma das categorias apresentadas, devido ao fato de haver alta incerteza na maioria das áreas do mundo, ligada à disponibilidade e confiabilidade dos dados por fonte de água. Apesar desta limitação dos métodos de avaliação, impossibilitando a análise dos impactos pela origem da água, o resultado 
do impacto na água superficial é de grande importância para a tomada de decisão na aplicação de medidas que atenuem o impacto ambiental.

A categoria de impacto avaliada na pegada de carbono foram as mudanças climáticas, com os resultados expressos em $\mathrm{Kg} \mathrm{CO}_{2}$ eq/L de água de coco. Utilizou-se o método do IPCC (2007), considerando o potencial de aquecimento global dos GEE no período de 100 anos.

\section{Análise de incerteza para interpretação dos resultados}

A análise de incerteza foi utilizada na avaliação comparativa dos sistemas estudados para determinar se houve diferença significativa nos resultados das pegadas obtidas entre as quatro fazendas produtoras e a fazenda de referência.

O método de Monte Carlo foi utilizado na análise de incerteza da comparação entre duas fazendas, denominadas de 1 e 2. Essa análise considerou os resultados de impacto de 1.000 simulações (Goedkoop et al. 2013). Analisa-se o percentual de ocorrência do impacto de $1<2$. Quando esse percentual é maior ou igual a 95\%, avalia-se que a diferença de impacto é significativa entre 1 e 2, podendo-se afirmar que a Fazenda 1 apresenta impacto menor que a Fazenda 2.

Para aplicação do método Monte Carlo, é necessário que seja definida uma função, valor médio e desvio padrão para cada parâmetro do inventário. Assumiu-se a distribuição log-normal para cada dado de inventário (consumos e emissões), enquanto o desvio padrão foi estimado aplicando-se a Matriz Pedigree, como indicado por Goedkoop et al. (2013).

\section{Resultados E Discussão}

\section{Inventário ambiental}

A Tabela 1 apresenta os inventários de produção de água de coco, considerando o valor médio dos dados obtidos para os 17 anos de vida de um pomar de coco, nas várias fazendas analisadas.

Tabela 1. Inventários por fazenda, para um ano médio.

\begin{tabular}{|c|c|c|c|c|c|c|}
\hline \multirow{2}{*}{ Discriminação } & \multirow{2}{*}{ Unidade } & \multicolumn{5}{|c|}{ Ano médio } \\
\hline & & Referência & A & $\mathrm{C}$ & $\mathrm{P}$ & $\mathrm{T}$ \\
\hline Densidade de plantas & $\mathrm{pl} / \mathrm{ha}$ & 205 & 157 & 115 & 148 & 133 \\
\hline \multicolumn{7}{|c|}{ PRODUÇÃO } \\
\hline Água de coco & $\mathrm{L} / \mathrm{pl}$ & 46,4 & 85,9 & 71,6 & 59,8 & 31,3 \\
\hline Frutos & Frutos/pl & 112,4 & 207,9 & 157,0 & 167,0 & 75,8 \\
\hline \multicolumn{7}{|c|}{ ENTRADAS } \\
\hline \multicolumn{7}{|c|}{ 1. Insumos } \\
\hline Área & $\mathrm{m}^{2} / \mathrm{pl}$ & 49 & 49 & 49 & 49 & 49 \\
\hline Água & $\mathrm{m}^{3} / \mathrm{pl}$ & 53,7 & 52,8 & 54,7 & 28,4 & 9,8 \\
\hline Energia & $\mathrm{KWh} / \mathrm{m}^{3}$ & 13,4 & 13,2 & 13,7 & 7,1 & 2,7 \\
\hline
\end{tabular}


2. Fertilizantes

\begin{tabular}{|c|c|c|c|c|c|c|}
\hline Corretor de solo & $\mathrm{Kg} / \mathrm{pl}$ & - & 3,6 & 4,6 & - & - \\
\hline Composto orgânico & $\mathrm{Kg} / \mathrm{pl}$ & 25,3 & 59,2 & 72,1 & 31,8 & 39,6 \\
\hline $\mathrm{N}$ & $\mathrm{Kg} / \mathrm{pl}$ & 2,61 & 3,44 & - & 3,61 & 3,30 \\
\hline $\mathrm{P}$ & $\mathrm{Kg} / \mathrm{pl}$ & 1.82 & 0,20 & 2,35 & 1,88 & 1.11 \\
\hline K & $\mathrm{Kg} / \mathrm{pl}$ & 2,19 & 2,25 & 0,00 & 3,53 & 2.62 \\
\hline Micronutrientes & $\mathrm{Kg} / \mathrm{pl}$ & 0,04 & 0,31 & 0,09 & - & - \\
\hline Sulfatos* & $\mathrm{Kg} / \mathrm{pl}$ & 0,23 & - & - & - & - \\
\hline Óxidos & $\mathrm{Kg} / \mathrm{pl}$ & - & - & - & 0,002 & - \\
\hline \multicolumn{7}{|c|}{ 3. Defensivos } \\
\hline Detergente & $\mathrm{L} / \mathrm{pl}$ & 0,10 & 0,00 & 0,14 & 0,28 & 0,02 \\
\hline Pesticidas & $\mathrm{Kg} / \mathrm{pl}$ & 0,03 & 0,03 & 0,02 & - & - \\
\hline Extrato vegetal & $\mathrm{L} / \mathrm{pl}$ & 0,14 & 0,01 & 0,41 & 0,41 & 0,03 \\
\hline \multicolumn{7}{|c|}{ 4. Mecanização } \\
\hline Pulverizações & Unidade/pl & 0,03 & 0,01 & 0,06 & 0,05 & 0,02 \\
\hline Roçagem & Unidade/pl & 0,01 & 0,03 & 0,03 & - & 0,01 \\
\hline \multicolumn{7}{|c|}{ 5. Transporte } \\
\hline Insumos & $\mathrm{Tkm} / \mathrm{pl}^{* * * *}$ & 25,1 & 40,4 & 34,9 & 32,7 & 28,4 \\
\hline \multicolumn{7}{|c|}{ SAÍDAS } \\
\hline \multicolumn{7}{|c|}{ 6. Emissões } \\
\hline \multicolumn{7}{|c|}{ 6.1 Mudança de uso da terra } \\
\hline Dióxido de carbono - $\mathrm{CO}_{2}$ & $\mathrm{Kg} / \mathrm{pl}$ & 10,17 & 13,45 & 18,57 & 14,30 & 15,98 \\
\hline Óxido nitroso $-\mathrm{N}_{2} \mathrm{O}$ & $\mathrm{Kg} / \mathrm{pl}$ & 0,002 & 0,003 & 0,004 & 0,003 & 0,004 \\
\hline Óxido de nitrogênio - $\mathrm{NO}_{\mathrm{x}}$ & $\mathrm{Kg} / \mathrm{pl}$ & 0,000 & 0,001 & 0,001 & 0,001 & 0,001 \\
\hline Monóxido de carbono - $\mathrm{CO}$ & $\mathrm{Kg} / \mathrm{pl}$ & 0,015 & 0,019 & 0,026 & 0,020 & 0,022 \\
\hline Metano $-\mathrm{CH}_{4}$ & $\mathrm{Kg} / \mathrm{pl}$ & 0,001 & 0,001 & 0,001 & 0,001 & 0,001 \\
\hline \multicolumn{7}{|c|}{ 6.2 Emissões para o ar } \\
\hline Amônia - $\mathrm{NH}_{4}$ & $\mathrm{Kg} / \mathrm{pl}$ & 0,246 & 0,272 & 0,165 & 0,066 & 0,321 \\
\hline Óxido nitroso $-\mathrm{N}_{2} \mathrm{O}$ & $\mathrm{Kg} / \mathrm{pl}$ & 0,091 & 0,080 & 0,040 & 0,094 & 0,071 \\
\hline Óxido de nitrogênio - $\mathrm{NO}_{\mathrm{x}}$ & $\mathrm{Kg} / \mathrm{pl}$ & 0,023 & 0,024 & 0,009 & 0,031 & 0,029 \\
\hline Dióxido de carbono $-\mathrm{CO}_{2}$ & $\mathrm{Kg} / \mathrm{pl}$ & 1,841 & 2,114 & 0,489 & 2,553 & 2,333 \\
\hline \multicolumn{7}{|c|}{ 6.3 Emissões para água superficial e subterrânea } \\
\hline Nitrato $-\mathrm{NO}_{3}$ & $\mathrm{Kg} / \mathrm{pl}$ & 25,59 & 20,96 & 11,19 & 23,62 & 15,92 \\
\hline Fósforo & $\mathrm{Kg} / \mathrm{pl}$ & 0,0001 & 0,0001 & 0,0001 & 0,0001 & 0,0001 \\
\hline Metais pesados & $\mathrm{Kg} / \mathrm{pl}$ & 0,0002 & 0,0004 & 0,0004 & 0,0003 & 0,0004 \\
\hline \multicolumn{7}{|c|}{ 6.4 Emissões para o solo } \\
\hline Metais pesados & $\mathrm{Kg} / \mathrm{pl}$ & 0,0013 & 0,0078 & 0,0010 & 0,0005 & 0,0012 \\
\hline
\end{tabular}

* Sulfato de zinco, sulfato de cobre e sulfato de manganês.

** Óxido de boro, óxido de cobre, óxido de manganês e óxido de zinco.

***Tonelada por quilômetro percorrido. 
A densidade de plantas por hectare em cada fazenda variou consideravelmente. No entanto, os valores permaneceram abaixo da densidade da fazenda de referência $(205 \mathrm{pl} / \mathrm{ha})$. A produção de água em $\mathrm{A}, \mathrm{C}$ e $\mathrm{P}$ foi maior que na situação de referência, enquanto em $T$ foi menor.

Com relação aos fertilizantes, a maioria das fazendas utiliza uma maior quantidade de composto orgânico por planta do que o indicado na fazenda de referência. As fazendas A, P e T fazem uso de uma maior quantidade de nitrogênio por planta com relação à referência, já a fazenda $C$ não utiliza nitrogênio a partir de fontes sintéticas.

Os valores de fósforo e potássio utilizados nas fazendas A, P e T são próximos e similares ao da fazenda de referência. No entanto, a fazenda $\mathrm{C}$ apresenta grande diferença, pois utiliza o dobro de fósforo recomendado pela referência e apenas $1,5 \%$ do potássio indicado.

A fazenda $\mathrm{P}$ aplica somente uma solução de detergente e extrato vegetal para o controle sanitário. As fazendas $\mathrm{C}$ e T, além dessa solução, aplicam também inseticidas. Já a fazenda de referência e a fazenda A aplicam uma maior variedade de defensivos, como herbicidas, fungicidas, formicidas, entre outros. A mecanização no processo de produção (roçagem e pulverização) é similar em todas as fazendas.

Com relação à mudança no uso da terra, a maior diferença foi observada nas emissões de dióxido de carbono, em que a fazenda $\mathrm{C}$ apresenta a maior emissão de $\mathrm{CO}_{2}$ cerca de $18,57 \mathrm{Kg}$ /planta, enquanto a produção referência possui a menor emissão, $10,17 \mathrm{Kg} \mathrm{CO}_{2}$ /planta. Isso ocorre devido ao menor estoque de carbono na área de produção da fazenda $\mathrm{B}$, que possui a menor quantidade de plantas por hectare. Nas demais fazendas a emissão é muito próxima.

As emissões para o ar, água e solo são similares em todas as fazendas, exceto a emissão de nitrato para a água, as fazendas $\mathrm{C}$ e $\mathrm{T}$ emitem um valor bem menor se comparado com as fazendas A, P e referência. Isso ocorre devido a menor taxa de absorção de nitrogênio pela cultura, pois as fazendas $\mathrm{C}$ e $\mathrm{T}$ possuem as menores quantidades de plantas por hectare.

Uso da água na irrigação

O volume de água de irrigação varia em função do manejo e da disponibilidade hídrica de cada região. As fazendas A e C utilizam um volume de água de irrigação similar ao da fazenda referência. Já os volumes em P e $T$ são menores que o da referência (Tabela 1 ).

A comparação do volume de água utilizado na produção de coco verde em cada fazenda com a necessidade hídrica do coqueiro-anão por região, considerando as condições climáticas, também mostra que o volume aplicado em A e C está próximo ao demandado pelo coqueiro, enquanto o aplicado em P e T é inferior ao necessário (Figura 1).

Figura 1. Necessidade hídrica do coqueiro em cada região e fazenda em comparação ao volume de água aplicado na irrigação. Região I: Acaraú e Camocim; Região II: Paraipaba e Trairi.

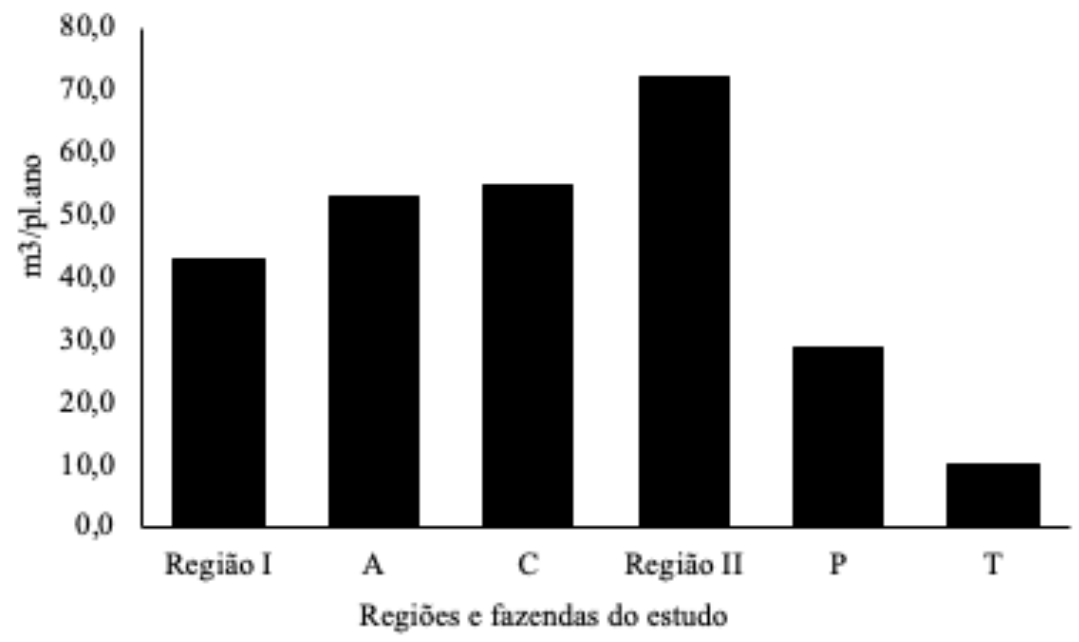


De acordo com Amorim et al. (2016), a falta de água para irrigação do coqueiro acarreta redução do crescimento da planta, queda prematura das folhas, retardamento do início da produção, frutos imaturos e de tamanho reduzido. Assim, infere-se que apesar da cultura do coco ser resistente ao estresse hídrico, a reduzida menor oferta hídrica em $\mathrm{P}$ e T reduziu a produção de coco e de água de coco.

Analisando o volume de água para irrigação e o volume de água de coco produzida, percebe-se que a otimização dessa relação, embora eficiente no uso do recurso água, pode afetar o desempenho econômico das fazendas de coco verde. Pela Tabela 1, tem-se que, na situação de referência, utiliza-se $1,16 \mathrm{~m}^{3} \cdot \mathrm{L}^{-1}$ de água de coco produzida, já nas demais situações esse valor varia de $0,76 \mathrm{~m}^{3} \cdot \mathrm{L}^{-1} \mathrm{em} \mathrm{C}$ a $0,31 \mathrm{~m}^{3} \cdot \mathrm{L}^{-1} \mathrm{em} \mathrm{T}$. Poderia ser inferido que a melhor situação ocorre em T. Porém, nessa situação, há menor produção de água por planta, gerando menor receita com a comercialização da água de coco. Assim, ressalta-se que a produção de água de coco requer irrigação em quantidade adequada para que a cocoicultura seja economicamente viável.

Considerando-se o consumo de água por quilo de fruto produzido $\left(0,23 \mathrm{~m}^{3} / \mathrm{Kg}\right.$ de coco verde) ao invés de por litro de água de coco $\left(1,15 \mathrm{~m}^{3} / \mathrm{L}\right)$, observa-se que essa relação é próxima a de outras culturas irrigadas no Nordeste. Considerando que há eficiência na irrigação, a produção de melão, por exemplo, demanda $0,15 \mathrm{~m}^{3} /$ $\mathrm{Kg}$ (Figueirêdo et al. 2014), enquanto a de manga, 0,37 $\mathrm{m}^{3} / \mathrm{Kg}$ (Carneiro et al. 2019).

A quantidade de energia gasta está relacionada com o volume de água utilizado na irrigação de cada fazenda e que pode ser vista na Tabela 1.

\section{Perfil da pegada bídrica}

Analisando o perfil de pegada hídrica, observa-se que os valores médios de impacto em $\mathrm{P}$ são menores que os da referência e demais fazendas, em quatro categorias de impacto: eutrofização em águas doces, toxicidade humana, câncer, não-câncer e ecotoxicidade (Tabela 2). Já C apresenta o pior perfil de pegada hídrica, pois os impactos na escassez hídrica, eutrofização em águas doces, toxicidade humana, câncer e ecotoxicidade foram maiores que nas outras fazendas, devido ao uso de maior quantidade de água para irrigação, composto orgânico e fósforo por planta, colaborando assim, para uma maior impacto nestas categorias (Tabela 1).

Tabela 2. Impactos nas categorias relacionadas à pegada hídrica.

\begin{tabular}{|c|c|c|c|c|c|c|}
\hline \multirow{2}{*}{$\begin{array}{l}\text { Categoria de } \\
\text { impacto }\end{array}$} & \multirow{2}{*}{ Unidade } & \multicolumn{5}{|c|}{ Local de produção da água de coco } \\
\hline & & Referência & Acaraú (A) & Camocim (C) & Paraipaba $(\mathrm{P})$ & Trairi $(\mathrm{T})$ \\
\hline Escassez hídrica & $\mathrm{m}^{3} \mathrm{eq} / \mathrm{L}$ & 2,91 & 2,16 & 3,16 & 1,86 & 1,53 \\
\hline $\begin{array}{l}\text { Eutrofização } \\
\text { em águas doces }\end{array}$ & $\mathrm{kg}$ P-eq/L & $1,23 \mathrm{E}-04$ & $6,85 \mathrm{E}-05$ & $1,41 \mathrm{E}-04$ & $6,20 \mathrm{E}-05$ & 7,70E-05 \\
\hline $\begin{array}{l}\text { Eutrofização } \\
\text { marinha }\end{array}$ & kg N-eq/L & 0,13 & 0,06 & 0,04 & 0,09 & 0,12 \\
\hline $\begin{array}{c}\text { Toxicidade } \\
\text { humana, câncer }\end{array}$ & CTUh/L & $2,60 \mathrm{E}-08$ & 2,77E-08 & 3,98E-08 & 2,14E-08 & $3,32 \mathrm{E}-08$ \\
\hline $\begin{array}{l}\text { Toxicidade } \\
\text { humana, não- } \\
\text { câncer }\end{array}$ & CTUh/L & $3,30 \mathrm{E}-07$ & 1,20E-07 & $1,85 \mathrm{E}-07$ & 1,04E-07 & 1,34E-07 \\
\hline $\begin{array}{l}\text { Ecotoxicidade } \\
\text { em águas doces }\end{array}$ & CTUe/L & 4,67 & 2,46 & 5,72 & 1,99 & 4,08 \\
\hline
\end{tabular}


Analisando os resultados para escassez hídrica calculados de acordo com AWARE (Boulay et al. 2018), observa-se que, em todas as situações de produção, os valores, quando se utiliza fator mensal de potencial de escassez em uma bacia (FC), são superiores aos valores obtidos quando se emprega fator anual (Figura 2). Assim, conclui-se que o impacto na escassez é sensível à escolha do fator de caracterização (anual ou mensal), duas opções fornecidas pelo método AWARE. Vázquez-Rowe et al. (2017b), avaliando a escassez hídrica da uva peruana, cultivada em região semiárida, também observaram grande variação nos resultados quando FC mensais ou anuais foram empregados.

O uso de fatores mensais torna o resultado mais sensível devido à relação positiva entre volume irrigado e mês com maior escassez hídrica. Observa-se que a produção em campo é o processo que mais contribui para o resultado de escassez hídrica (Figura 2), devido ao grande volume de água necessário para irrigação do coqueiro que ocorre nos meses de estiagem (junho a janeiro). Locais que sofrem historicamente com a escassez hídrica, como o semiárido brasileiro, apresentam maiores FC, especialmente em meses de pouca precipitação, que usualmente são os meses quando a irrigação é mais necessária.

Assim, quando o cálculo do impacto considera a escassez mensal, seu valor é sempre superior ao da situação em que o FC anual é empregado. FC anuais são gerados considerando a média de escassez em todos os meses do ano, alguns meses apresentando alto FC (estação seca) e em outros, baixo FC (estação chuvosa).

Figura 2. Impactos da escassez hídrica.

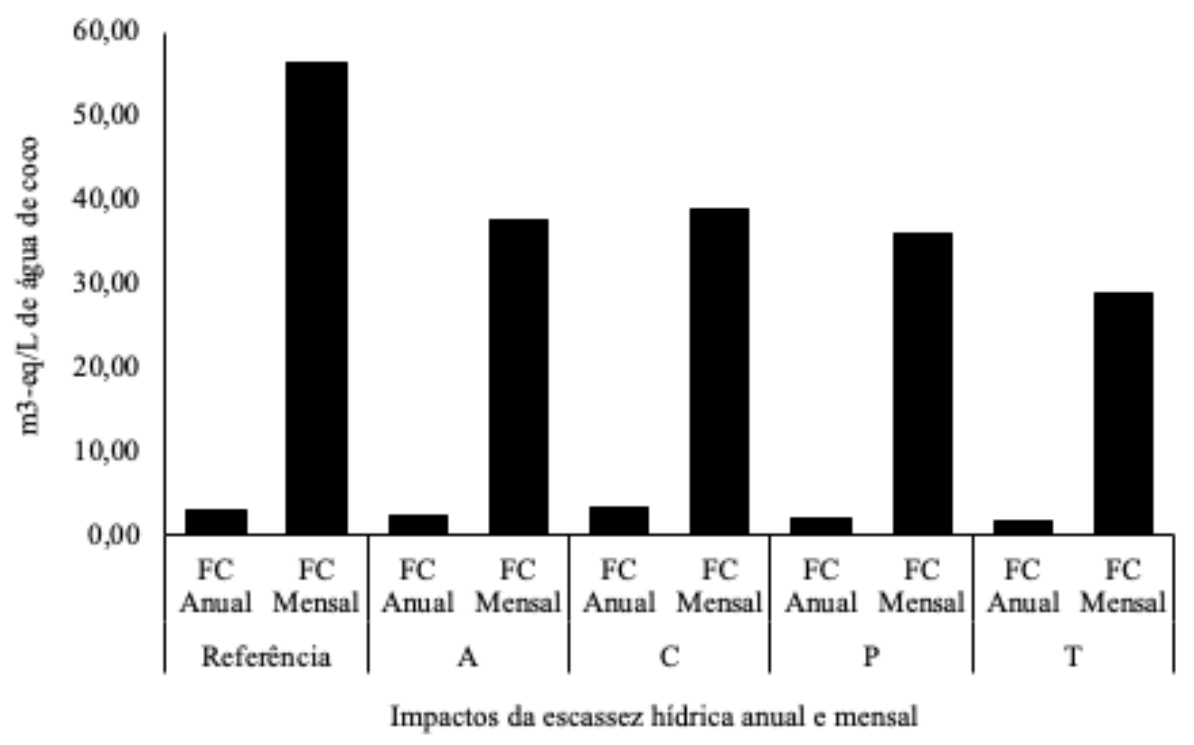

Os valores de escassez deste trabalho, calculados com FC anual, foram comparados com os obtidos por Sampaio et al. (2018) para a água produzida no Ceará. Observa-se que a variação informada por esses autores do impacto da água de coco na escassez foi de 2,34 a 17,77 $\mathrm{m}^{3}$ eq/L. A fazenda A apresentou um valor abaixo do mínimo informado $\left(2,20 \mathrm{~m}^{3} \mathrm{eq} / \mathrm{L}\right)$, enquanto as demais fazendas avaliadas neste trabalho apresentaram valores dentro da variação encontrada por Sampaio et al. (2018).

Todas as atividades do sistema de produção foram agrupadas em cinco processos: mudança no uso da terra, produção em campo (uso dos insumos), produção e transporte dos insumos utilizados, operações agrícolas (mecanizadas) e irrigação. A figura 3 apresenta os processos que mais impactaram na categoria de escassez hídrica, sendo elas a produção em campo e a produção e transporte dos insumos em todos os sistema de produção de coco analisados. 
Figura 3. Contribuição dos processos na escassez hídrica por fazenda.

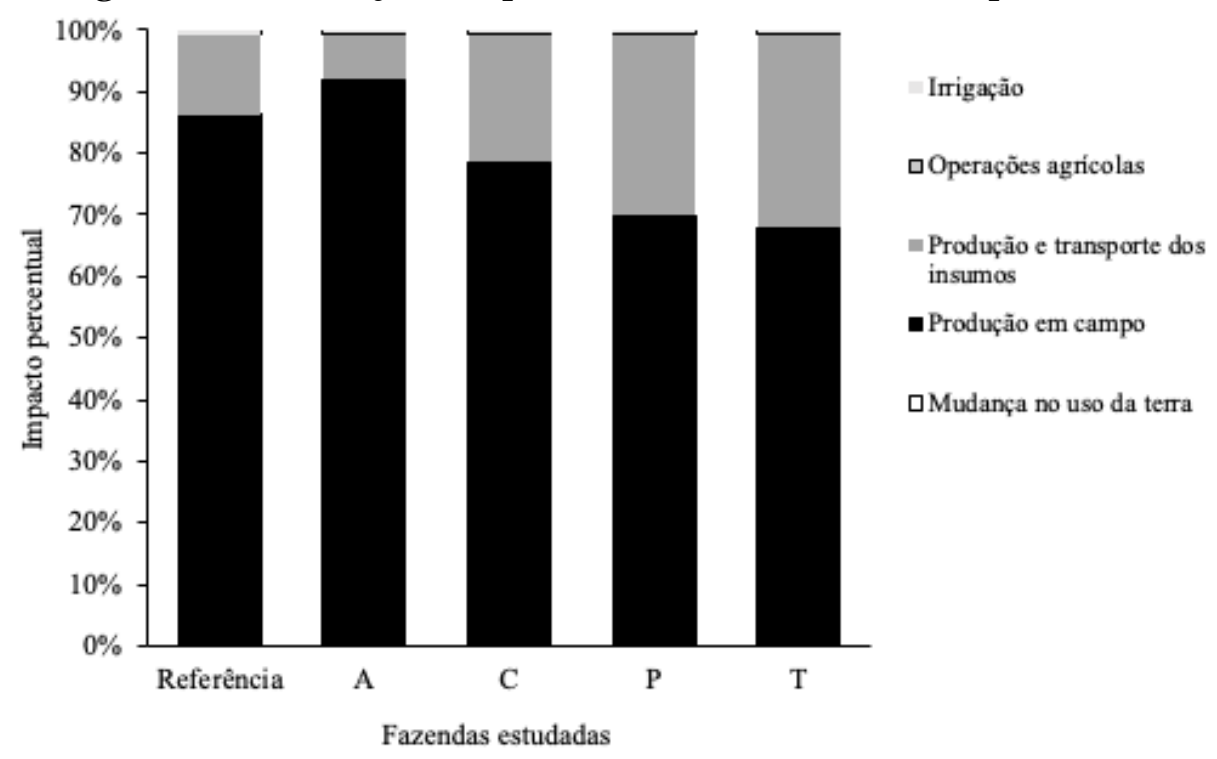

Perfil da pegada hidrica: demais categorias

$\mathrm{Na}$ categoria de eutrofização de água doce, observa-se que o impacto da água de coco em P é em média 42\% menor que na fazenda referência, enquanto em C, 17\% maior (Figura 4). A análise de dominância revela que a produção e transporte dos fertilizantes é o processo mais impactante na eutrofização de água doce, em todas as situações de produção avaliadas (Figura 4). Isso decorre das emissões de fósforo na extração do fósforo mineral e na produção de composto orgânico.

Em relação à eutrofização marinha, os melhores resultados ocorreram em A e C, cujos impactos são, respectivamente, 47 e 69\% menores que na referência (Figura 4). O processo que mais impacta a eutrofização marinha é a produção do coco em campo, contribuindo com quase 100\% do impacto em todas as situações (Figura 4). Esse resultado deve-se principalmente as emissões de nitrato oriundas dos fertilizantes nitrogenados aplicados no coqueiral.

Figura 4. Contribuição dos processos na eutrofização por fazenda.

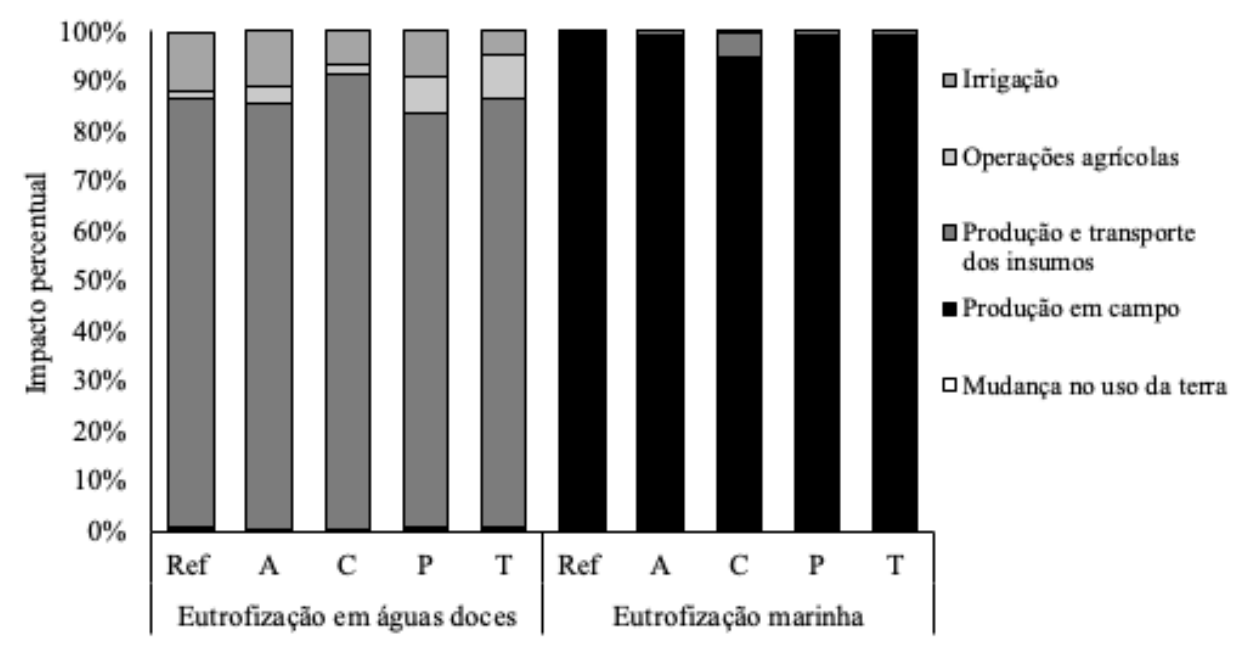

$\mathrm{Na}$ toxicidade humana, não-câncer, o melhor desempenho encontrado foi em $\mathrm{P}$, que apresenta um impacto 60\% inferior ao da referência (Tabela 2). O pior desempenho nesta categoria foi do sistema da referência. $O$ processo mais impactante na referência, em A, P e T foi a produção e transporte dos insumos (Figura 5); entre 
os quais os pesticidas utilizados, a partir de substâncias nocivas como o acefato, aldrina e furano, empregados na produção de algodão que é a matéria-prima para o óleo empregado como defensivo na produção de coco verde.

Por fim, na ecotoxicidade, o melhor desempenho ocorreu em $\mathrm{P}$ e o pior, em C (Tabela 2). A produção agrícola do coco e a produção e transporte dos insumos se mostraram as etapas mais impactantes dessa categoria, contribuindo, juntas, com aproximadamente $95 \%$ do impacto, em todas os sistemas de produção de coco avaliados (Figura 5).

Figura 5. Contribuição dos processos na toxicidade por fazenda.

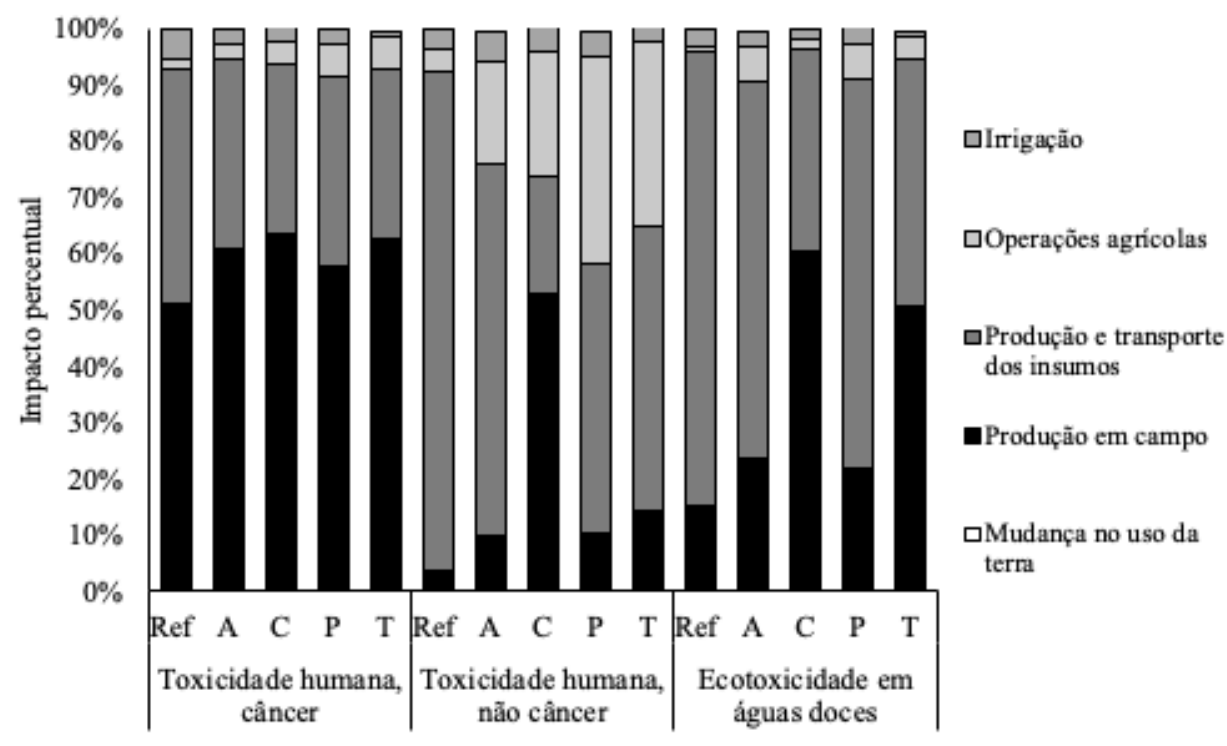

\section{Pegada de carbono}

$\mathrm{Na}$ avaliação da pegada de carbono, considera-se a categoria mudanças climáticas. Observa-se que o valor de impacto na situação de referência é semelhante ao encontrado em P. Entretanto, a água de coco em A e C apresentaram um impacto 40\% menor que na referência, enquanto em T, 58\% maior (Figura 6).

Figura 6. Contribuição de processos para pegada de carbono por fazenda.

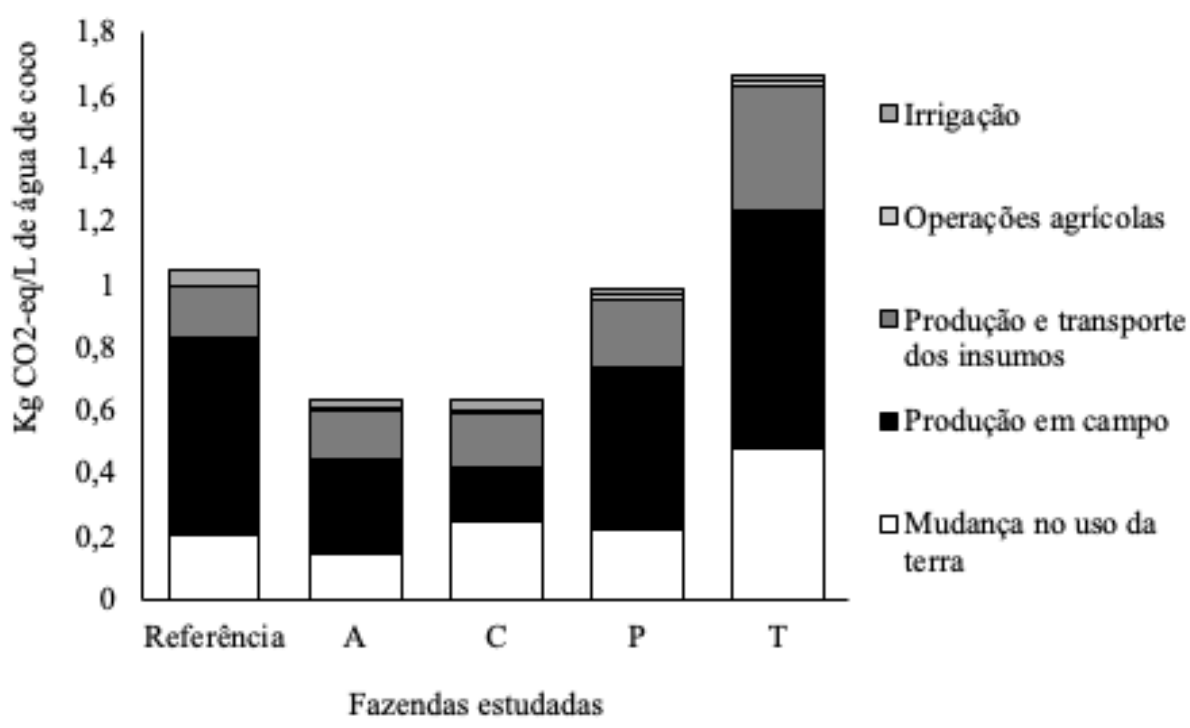


A principal razão para o melhor desempenho em $\mathrm{A}$ e $\mathrm{C}$ são as maiores produções de água de coco por planta, 85,9 e 71,6 L, respectivamente, que é duas vezes superior à da situação de referência. Como a pegada é aferida por litro de água de coco, quanto mais água é gerada por planta, menor é o impacto. As emissões de gases de efeito estufa são similares entre as fazendas analisadas neste trabalho e a situação de referência.

Buscando identificar os processos que mais afetam a pegada de carbono, avaliou-se a contribuição dos processos ao longo da cadeia produtiva. Observa-se que nas fazendas de referência A, P e T o processo que mais contribui para pegada de carbono é a produção em campo, devido às emissões de dióxido de carbono e óxido nitroso decorrentes da aplicação dos fertilizantes sintéticos nitrogenados (Figura 6). O segundo processo mais impactante é a mudança de uso da terra, devido à transformação da vegetação de caatinga para pomar com coqueiro anão, e consequente redução do estoque de carbono na biomassa e no solo. Somente na fazenda $\mathrm{C}$ o oposto é observado, sendo a mudança de uso da terra o processo mais impactante na produção de água de coco.

Vega (2011) investigou oportunidades para a redução da emissão de carbono na produção de coco nas Filipinas. Dentre as oportunidades abordadas, avaliaram-se opções para a mudança de uso do solo, em que a conversão de terras para o cultivo de coqueiros pode agravar ou melhorar as emissões de carbono, dependendo da categoria original do uso do solo. Um exemplo seria a conversão de pastagens e terras degradadas para coqueirais, na qual se estima uma redução média de 3,5 tC.ha- $\mathrm{ano}^{-1}$ Por outro lado, a conversão de florestas tropicais pode resultar em um aumento da emissão de carbono de cerca de 3,6 tC.ha- . ano $^{-1}$ (Vega 2011).

Estudos anteriores avaliando a pegada de carbono de outras frutas perenes cultivadas do nordeste brasileiro também mostraram a importância do tipo de vegetação existente na área onde a cultura é estabelecida. Figueirêdo et al. (2015) mostraram que o menor impacto da produção de caju nas mudanças climáticas ocorreu quando a área era anteriormente ocupada com cultura temporária, como milho. Carneiro et al. (2019) também avaliaram que a menor pegada de carbono da manga ocorre quando o pomar é instalado em área produtora de melão ou outra cultura temporária.

Observou-se também que a pegada de carbono da cultura do coco nas fazendas de referência, A, C e P, foi próxima ou menor que os valores apresentados por outros frutos irrigados (Tabela 3). Exceto na fazenda $\mathrm{T}$, no qual o impacto na mudança climática foi superior aos da banana e abacaxi costa riquenhos (Svanes e Aronsson 2013; Ingwersen 2012), mirtilo e cereja chilenos (Cordes et al. 2016; Bravo et al. 2017) e melão e manga brasileiros (Santos et al. 2018; Carneiro et al. 2019). Já a pegada hídrica do coqueiro brasileiro, na categoria escassez hídrica foi superior aos impactos encontrados por Vázquez-Rowe et al. (2017b) para a uva peruana e por Carneiro et al. (2019) para a manga brasileira.

Tabela 3. Comparação da pegada de carbono e hídrica do coco com a de outros frutos irrigados.

\begin{tabular}{lc}
\hline \multicolumn{1}{c}{ Pegada de carbono (mudança climática) } & $\mathrm{Kg} \mathrm{CO}_{2}$ eq / Kg \\
\hline Coco, faz. Ref, este estudo & 1,05 \\
Coco, faz. A, este estudo & 0,63 \\
Coco, faz. C, este estudo & 0,63 \\
Coco, faz. P, este estudo & 0,99 \\
Coco, faz. T, este estudo & 1,66 \\
Banana, Costa Rica (Svanes e Aronsson 2013) & 1,37 \\
Mirtilo, Chile (Cordes et al. 2016) & 0,57 \\
Cereja, Chile (Bravo et al. 2017) & 0,41 \\
Melão, Brasil (Santos et al. 2018) & 0,75 \\
Manga, Brasil (Carneiro et al. 2019) & 0,13 \\
Abacaxi, Costa Rica (Ingwersen 2012) & 0,14 \\
\hline
\end{tabular}




\begin{tabular}{lc}
\hline \multicolumn{1}{c}{ Pegada hídrica (escassez hídrica) } & $\mathrm{m}^{3}$ eq / Kg \\
\hline Coco, faz. Ref, este estudo & 2,91 \\
Coco, faz. A, este estudo & 2,16 \\
Coco, faz. C, este estudo & 3,16 \\
Coco, faz. P, este estudo & 1,86 \\
Coco, faz. T, este estudo & 1,53 \\
Uva, Peru (Vázquez-Rowe et al. 2017b) & 0,21 \\
Manga, Brasil (Carneiro et al. 2019) & 0,93 \\
\hline
\end{tabular}

\section{Análise de incertez̧a}

Com relação à pegada de carbono, a análise de incerteza mostra que a diferença de pegada da água de coco produzida na situação de referência e em A e T é significativa (Tabela 4). A água de coco produzida na situação de referência (1) apresentou pegada maior que em A, porém, menor que em $T$.

$\mathrm{Na}$ pegada hídrica, a análise de incerteza mostra que os impactos em A são significativamente menores que na situação de referência em quase todas as categorias, com exceção de escassez hídrica e toxicidade humana câncer (Tabela 4). Para essas duas últimas categorias, embora os impactos de A sejam em média menores que os da fazenda referência, não se pode afirmar que essa diferença seja significativa, pois em mais de 5\% das simulações o valor da referência foi menor que A (valor de escassez na Referência < A em 11\% das simulações, e valor da toxicidade, em 22,9\%).

A análise de incerteza da fazenda $\mathrm{C}$ mostra que os impactos são significativamente menores com relação à situação de referência em quase todas as categorias, com exceção das categorias de escassez hídrica e eutrofização em águas doces (Tabela 4). O resultado da análise dessas duas categorias não permite afirmar que essa diferença seja significativa, pois em mais de 5\% das simulações o valor da referência foi menor que C.

$\mathrm{Na}$ fazenda $\mathrm{P}$, a análise de incerteza mostra que os impactos são significativamente menores com relação à situação de referência também em quase todas as categorias, com exceção de escassez hídrica e eutrofização marinha (Tabela 4). Para essas categorias não é possível afirmar que a diferença seja significativa, pois o valor da referência foi menor que $\mathrm{P}$ em mais de $5 \%$ das simulações.

$\mathrm{Na}$ fazenda $\mathrm{T}$ os resultados da análise de incerteza mostram que os impactos são significativamente menores com relação à situação de referência somente nas categorias de eutrofização em águas doces e ecotoxicidade em águas doces (Tabela 4). Nas demais categorias não foi possível afirmar que a diferença foi significativa, pois o valor da referência, em mais de 5\% das simulações, foi menor que $\mathrm{T}$.

Tabela 4. Análise de incerteza para pegadas de carbono e hídrica.

\begin{tabular}{|c|c|c|c|c|c|}
\hline Pegada & Categoria de impacto & Unidade & Situação 1 & Situação 2 & $1<2(\%)$ \\
\hline \multirow{4}{*}{ Carbono } & \multirow{4}{*}{ Mudanças climáticas } & \multirow{4}{*}{$\mathrm{CO}_{2}$-eq/L } & \multirow{4}{*}{ Referência } & Acaraú (A) & $0,1 \%$ \\
\hline & & & & Camocim $(\mathrm{C})$ & $20,8 \%$ \\
\hline & & & & Paraipaba (P) & $22,1 \%$ \\
\hline & & & & Trairi $(\mathrm{T})$ & $99,3 \%$ \\
\hline
\end{tabular}




\begin{tabular}{|c|c|c|c|c|c|}
\hline Pegada & Categoria de impacto & Unidade & Situação 1 & Situação 2 & $1<2(\%)$ \\
\hline \multirow{24}{*}{ Hídrica } & \multirow{4}{*}{ Escassez hídrica } & \multirow{4}{*}{$\mathrm{m}^{3} / \mathrm{L}$} & \multirow{4}{*}{ Referência } & Acaraú (A) & $11 \%$ \\
\hline & & & & Camocim (C) & $42,5 \%$ \\
\hline & & & & Paraipaba (P) & $13 \%$ \\
\hline & & & & Trairi $(\mathrm{T})$ & $6 \%$ \\
\hline & \multirow{4}{*}{$\begin{array}{c}\text { Eutrofização em águas } \\
\text { doces }\end{array}$} & \multirow{4}{*}{ kg P-eq/L } & \multirow{4}{*}{ Referência } & Acaraú (A) & $0,3 \%$ \\
\hline & & & & Camocim (C) & $65 \%$ \\
\hline & & & & Paraipaba $(\mathrm{P})$ & $0,5 \%$ \\
\hline & & & & Trairi $(\mathrm{T})$ & $1,1 \%$ \\
\hline & \multirow{4}{*}{ Eutrofização marinha } & \multirow{4}{*}{$\mathrm{kg} \mathrm{N}$-eq/L } & \multirow{4}{*}{ Referência } & Acaraú (A) & $0,8 \%$ \\
\hline & & & & Camocim (C) & $0 \%$ \\
\hline & & & & Paraipaba $(\mathrm{P})$ & $12,1 \%$ \\
\hline & & & & Trairi (T) & $45,7 \%$ \\
\hline & \multirow{4}{*}{$\begin{array}{l}\text { Toxicidade humana, } \\
\text { câncer }\end{array}$} & \multirow{4}{*}{ CTUh/L } & \multirow{4}{*}{ Referência } & Acaraú (A) & $22,9 \%$ \\
\hline & & & & Camocim (C) & $100 \%$ \\
\hline & & & & Paraipaba (P) & $0 \%$ \\
\hline & & & & Trairi (T) & $51,7 \%$ \\
\hline & \multirow{4}{*}{$\begin{array}{l}\text { Toxicidade humana, } \\
\text { não-câncer }\end{array}$} & \multirow{4}{*}{ CTUh/L } & \multirow{4}{*}{ Referência } & Acaraú (A) & $0,7 \%$ \\
\hline & & & & Camocim (C) & $100 \%$ \\
\hline & & & & Paraipaba (P) & $100 \%$ \\
\hline & & & & Trairi $(\mathrm{T})$ & $28,6 \%$ \\
\hline & \multirow{4}{*}{$\begin{array}{c}\text { Ecotoxicidade em águas } \\
\text { doces }\end{array}$} & \multirow{4}{*}{ CTUe/L } & \multirow{4}{*}{ Referência } & Acaraú (A) & $0 \%$ \\
\hline & & & & Camocim (C) & $100 \%$ \\
\hline & & & & Paraipaba $(\mathrm{P})$ & $0,5 \%$ \\
\hline & & & & Trairi $(\mathrm{T})$ & $100 \%$ \\
\hline
\end{tabular}

\section{Conclusão}

Em relação à fazenda de referência, a água de coco produzida em Acaraú e Camocim apresentaram a menor pegada de carbono, enquanto Paraipaba a menor pegada hídrica. Já a água de coco de Trairi obteve a pior pegada de carbono, enquanto a de Camocim, a pior pegada hídrica. Assim, nas ações futuras voltadas para redução dessas pegadas, ou seja, a diminuição dos impactos da produção de coco verde, indica-se priorizar as fazendas localizadas nos municípios de Trairi e Camocim.

Para redução da pegada de carbono, deve-se optar pela instalação de pomar em área desmatada e/ou cultivada com cultura temporária há mais de 20 anos. No caso da pegada hídrica, deve-se melhorar a eficiência do uso de fertilizante nitrogenado e da irrigação. As fazendas de Acaraú, Paraipaba e Trairi podem reduzir o uso de fertilizante nitrogenado, enquanto a de Camocim, de fertilizante fosfatado.

Com relação à irrigação, a ineficiência no uso da água está relacionada ao menor volume aplicado, principalmente em Trairi e Paraipaba, em relação ao requerido para o desenvolvimento satisfatório da cultura. $\mathrm{O}$ menor volume de água usada na irrigação está relacionado com a menor produção de água de coco nas fazendas analisadas. 


\section{REFERÊNCIAS}

Amorim JRA, Miranda FR, Nogueira LC, Resende RS. Irrigação. In: Fontes HR, Ferreira JMS. A cultura do coqueiro. Disponível em: <https://www.spo.cnptia.embrapa.br.>. Acesso em: 12 abr. 2017.

Boulay AM, Bare J, Benini L, Berger M, Lathullière MJ, Manzardo A, Margni M, Motoshita M, Núñez M, Pastor AV, Ridoutt M, Oki T, Worbe S, Pfister S. 2018. The WULCA consensus characterization model for water scarcity footprints: Assessing impacts of water consumption based on available water remaining (AWARE). The International Journal of Life Cycle Assessment, v. 23, n. 2, p. 368 - 378.

Brainer MSCP. 2018. Produção de coco: o Nordeste é destaque nacional. Caderno Setorial ETENE, Banco do Nordeste, ano 3, n. 61.

Bravo G, López D, Vásquez M, Iriarte A (2017) Carbon footprint assessment of sweet cherry production: hotspots and improvement options. Journal of Environmental Studies, v. 26, n. 2, p. 559-566.

Carneiro JM, Dias AF, Barros VS, Giongo V, Matsuura MISF, Figueirêdo MCB. 2019. Carbon and water footprints of Brazilian mango produced in the semiarid region. The International Journal of Life Cycle Assessment, v. 24, n. 4, p. $735-752$.

Cordes H, Iriarte A, Villalobos P. 2016. Evaluating the carbon footprint of Chilean organic blueberry production. The International Journal of Life Cycle Assessment, v. 21, p. 281-292.

Emmenegger MF, Reinhard J, Zah R. 2009. Sustainability quick check for biofuels. Intermediate background report. Agroscope Reckenholz-Tänikon, Dübendorf. 129 p.

Figueirêdo MCB, Potting J, Serrano LAL, Bezerra MA, Barros VS, Gondim RS, Nemecek T. 2015. Environmental assessment of tropical perennial crops: the case of the Brazilian cashew. Journal of Cleaner Production, v. 112, n. 1, p. $131-140$.

Figueirêdo MCB, De Boer IJM, Kroeze C, Barros VS, De Sousa JÁ, De Aragão FAS, Gondim RS, Potting J. Reducing the impact of irrigated crops on freshwater availability: the case of Brazilian yellow melons. 2014. The International Journal of Life Cycle Assessment, v. 19, n. 2, p. 437 - 448.

Fontes HR, Ferreira JMS. 2016. A cultura do coqueiro. Aracaju: Embrapa - Tabuleiros Costeiros. Disponível em : <https:// www.spo.cnptia.embrapa.br.>. Acesso em: 12 abr. 2019.

Frischknecht R, Jungbluth N. 2007. Ecoinvent: overview and methodology. Dubendorf: Swiss Centre for Life Cycle Inventories. $77 \mathrm{p}$.

Goedkoop M, Oele M, Leijting J, Ponsioen T, Meijer E. 2013. Simapro8: Introduction to LCA with SimaPro. Netherlands: PRé-Consultants. 80 p.

Ingwersen WW. 2012. Life cycle assessment of fresh pineapple from Costa Rica. Journal of Cleaner Production, v. 35, p. 152-163.

Instituto Brasileiro de Geografia e Estatística (IBGE). Cidades. Disponível em: 〈https://cidades.ibge.gov.br/>. Acesso em: 23 out 2018. 
Intergovernmental Panel on Climate Change (IPCC). 2007. Climate Change 2007: The Physical Science Basis. Contribution of Working Group I to the Fourth Assessment Report of the Intergovernmental Panel on Climate Change. Cambridge University Press, Cambridge, United Kingdom and New York, NY, USA. 1007 p.

International Organization for Standardization (ISO). 2006. ISO 14025: environmental labels and declarations - Type III environmental declarations - Principles and procedures. Genebra. 25 p.

International Organization for Standardization (ISO). 2006a. ISO 14040: environmental management - Life cycle assessment - Principles and framework. Genebra. 20 p.

International Organization for Standardization (ISO). 2006b. ISO 14044: environmental management - Life cycle assessment - Requirements and guidelines. Genebra. 46 p.

International Organization for Standardization (ISO). 2014. ISO 14046: 2014- Environmental management - Water footprint - Principles, requirements and guidelines. Genebra. 33 p.

International Organization for Standardization (ISO). 2013. ISO 14067: 2013- Greenhouse gases - Carbon footprint of products - Requirements and guidelines for quantification and communication. Genebra. $52 \mathrm{p}$.

International Reference Life Cycle Data System (ILCD). 2011. Handbook: recommendations for life cycle impact assessment in the European context. Luxemburg: Publications Office of the European Union. 159 p.

Luske B. 2010. Comprehensive Carbon Footprint Assessment of Dole Bananas. Waddinxveen, Soil \& More International. Disponível em: <http://dolecrs.com/uploads/2012/06/Soil-More-Carbon-Footprint-Assessment.pdf >. Acesso em: 12 abr. 2019.

Miranda FR, Gomes ARM, Oliveira CHC, Montenegro AAT, Bezerra FML. 2007. Evapotranspiração e coeficientes de cultivo do coqueiro anão-verde na região litorânea do Ceará. Revista Ciência Agronômica, v. 38, p. 129-135.

Miranda FR, Gomes ARM. 2006. Manejo da irrigação Coqueiro-Anão. Embrapa Agroindústria Tropical. Fortaleza/CE. $8 \mathrm{p}$.

Nemecek T, Schinetzer J. 2011. Methods of assessment of direct field emissions for LCIs of agricultural production systems. Zurich. 34 p.

Rosenbaum RK, Bachmann TM, Gold LS, Huijbregts MAJ, Jolliet O, Juraske R, Kohler A, Larsen HF, MacLeod M, Margni M, McKone TE, Payet J, Schuhmacher M, Van De Meent D, Hauschild MZ. 2008. USEtox - the UNEP-SETAC toxicity model: recommended characterization factors for human toxicity and freshwater ecotoxicity in life cycle impact assessment. The International Journal of Life Cycle Assessment, v. 13, n. 7, p. 532.

Santos TL, Nunes ABA, Giongo V, Barros VS, Figueirêdo MCB. 2018. Cleaner fruit production with green manure: The case of Brazilian melons. Journal of Cleaner Production, v. 181, p. 260-270.

Sampaio APC, Silva AKP, Barros VS, Amorim JRA, Miranda FR, Figueirêdo MCB. 2018. Pegada hídrica da água de coco verde nas principais regiões produtoras do Nordeste. LALCA - Revista Latino-Americana em Avaliação do Ciclo de Vida, v. 1, p. 128-141. 
Sikirica N. 2011. Water Footprint Assessment Bananas and Pineapples. Driebergen, Soil \& More International. Disponível em: <http://dolecrs.com/uploads/2012/06/Soil\%20\&\%20More\%20Water\%20Footprint\%20Assessment.pdf >. Acesso em: 12 abr. 2019.

Svanes E, Aronsson AKS. 2013. Carbon footprint of a Cavendish banana supply chain. The International Journal of Life Cycle Assessment, v. 18, n. 8, p. 1450-1464.

Tesco. 2019. Ourcarbon footprint. Disponível em: <https://sustainability.tescoplc.com/sustainability/foundations/topics/ carbon-footprint/>. Acesso em: 12 abr. 2019.

United Nations Environmental Programe(UNEP). 2016. Global Guidance for Life Cycle Impact Assessment Indicators. Volume 1. 166 p.

Vázquez-Rowe I, Torres-García JR, Cáceres AL, Larrea-Gallegos G, Quispe I, Kahhat R. 2017b. Assessing the magnitude of potential environmental impacts related to water and toxicity in the Peruvian hyper-arid coast: A case study for the cultivation of grapes for pisco production. Science of the Total Environment, v. 601-602, p. 532-542.

Vega EV. 2011. Cleaner production opportunities for improvement of carbon saving in the production of coconut biodiesel. International Journal of Chemical and Environmental Engineering, v. 2, n. 5, p. 356 - 361. 